EPOS, XIII (1997), págs. 303-313

\title{
THE PREDICATIVE FUNCTION OF ADJECTIVES ${ }^{1}$
}

\author{
Jesús Gerardo Martinez del Castillo
}

Universidad de Yaounde I (Camerún)

\section{ABSTRACT}

Adjectives form a structure of predication made on the base of three components: the semantic component, the predicative component and the syntactic component. The semantic component is the base for the adjective to mean and relate with other words; the predicative component is the base for the adjective to create a predication; and the syntactic component is the manifestation of the other two, that is, the external manifestation of the adjective. When an adjective is in a combination the semantic structure of the combination is the display of the structure of meaning in the adjective. Both the semantic component and the predicative component of adjectives need definition and specification. The aim of this article is to analyse the predicative definition of the adjective and the functions it performs when it enters a combination.

1 This article is part of the program «Desarrollo de una lógica léxica para la traducción asistida por ordenador a partir de una base de datos léxica inglés-español-alemán-francés multifuncional y reutilizable», DGI CYT PB 94-0437. 


\section{The MEANING OF ADJECTIVES}

Adjectives exist in function of the nouns they are combined with (Martín Mingorance, 1985: 311). From a semantic point of view adjectives are elements that convey the expression of a particular dimension which is defined and specified by the noun they are combined with in the linguistic act. Adjectives are the expression of an open dimension of meaning not defined or specified in itself but with possibilities of definition and specification at any of its points. Adjectives are elements of meaning that need definition as to the meaning they convey, and specification as to the extent of the meaning they convey. From a semantic point of view adjectives can be analysed as elements of meaning having denotation ${ }^{2}$, but lacking definition and specification of the meaning they convey, lacking determination ${ }^{3}$, and lacking designation ${ }^{4}$. Adjectives do not exist in themselves but in terms of the elements they are combined with, that is, in terms of the nouns they are combined with which act as the heads of the combination where adjectives appear.

\section{ThE COMBINATION OF ADJECTIVES}

When adjectives appear in combination they are the base of the relationships of signification in the combination where they appear. From a syntactic point of view adjectives perform two functions which have to do with the potential capability of combination of adjectives, that is, with the predicative force of adjectives: the attributive function and the predicative function. In both cases, the adjective is the element that creates a predication ${ }^{5}$, that is, the element that creates a state of affairs ${ }^{6}$ with different relationships of signification between the components of the denotation of both the noun and the adjective. Both denotations are different states of affairs with capability of designation in the things in the world. In the combination they are decomposed in the component parameters of meaning making up the state of affairs that

2 With this expression 1 mean the systematization of the facts of experience made by the language, corresponding to meaning by Coseriu (cf. the levels of linguistic content by Coseriu (COSERIU, 1992: 96).

${ }^{3}$ Cf. Coseriu (Coseriu, 1982: 291-309).

4 Cf. the levels of linguistic content by Coseriu (Coseriu, 1992: 96).

5 Cf. Dik (Dik 1981: chapter 2).

- I use the expression 'state of affairs', taken from Dik (DiK, 1981: chapter 3 and 1979: chapter 5), meaning the particular rearrangement of experience denoted in a particular word or expression. 
they potentially denote and are rearranged so as to denote a new state of affairs. The predicative relationships of signification established in the combination of adjectives is a series of relationships of signification established by adjectives on other series of relationships of signification. The combination of adjective plus noun is a new predication, a new state of affairs made up on the states of affairs given by noun, taking the adjective as the base of the new meaning conveyed.

\section{THE PREDICATIVE FORCE OF ADJECTIVES}

Adjectives have capability of combination and predication. They are elements that accept within their own structure of meaning the parameters of meaning of other elements of meaning, thus forming a structure of predication. They are predicates which accept within their own structure of predication the complex relationships of signification that nouns can contribute with to the combination. The result is a new state of affairs, a new predication, a new set of relationships of signification which primarily consists in the extension of the parameters of meaning in the adjective. The new predication is made up of the following components: the denotation of the noun with capability of designation and, very important, with capability of determination; the denotation of the adjective, the expression of an open dimension of meaning which in itself is not defined or specified, but by the mere fact of the combination with nouns is defined as to the meaning it conveys, and specified as to the extent of that meaning. This definition and specification of the dimension of meaning of the adjective has to do with the determination of adjectives. In themselves adjectives are the expression of potential and abstract relationships of signification; in the combination they acquire the determination that orientates those potential and abstract relationships of signification to things in the real world ${ }^{7}$; and the predicative force of the adjective, the element that puts together both denotations and gives the base for the new state of affairs to exist. The new predication, thus, is a new state of affairs which performs the potentiality of meaning of the elements taking part in the combination, to mean and refer the things in the real world, thus constituting an instrument of communication and an instrument to fulfil the needs of expression of speakers.

${ }^{7}$ Coseriu (CoSERIU, 1985: 248-248) speaks of the determination of nouns by specific processes with the help of particular function words, determiners. This process of determination applies as well to adjectives. 


\subsection{Predicative character}

But the base of the predication is constituted by the adjective. The predicative force of the adjective is the element that puts together both states of affairs. Adjectives take up the meaning of the noun and integrate it into their structure of meaning as the execution of one of the parameters of meaning in their own structure of meaning. From a syntactic point of view adjectives perform two predicative functions: the syntactic attributive function and the syntactic predicative function. They both have to do with the ordering of words, but have certain semantic implications: the syntactic attributive function stresses the meaning and the function of the adjective, that is, the dimension of meaning of the adjective and the implicit predicative force of the combination; and the syntactic predicative function stresses the meaning and the function of the noun, that is, the denotation and the designation of the combination. In the pair of combinations,

the old house, and the house is old,

the state of affairs in the attributive function stresses the fact of something being old, and, then, specifies that fact restricting it with the specification of the thing predicated. The first aspect predicated is the dimension of meaning of the adjective, and, then, that dimension is restricted by the content of another element of meaning which is determined and has (or can have) designation in the real world. It can be paraphrased as «the oldness of the house», or, more precisely, «the oldness specified by the house». It is the oldness the first thing denoted; in predicative function, however, the thing meant is primarily the element of meaning with determination and designation in the real world, and, then, it is described with one of the possible characteristics it may have. The paraphrase in this case is tautological: «the house has the characteristic of being old». That is, in the attributive function the thing predicated is the content of the adjective, and in the predicative function it is the content of the noun. It is the contrast between the expression of an open dimension of meaning defined, specified, determined and given designation by the meaning of a noun, and the fact of the existence of a semantic object, determined and with designation, modified by the meaning of an adjective.

The most characteristic function and proper to the nature of the adjective, is the attributive function. The adjective acts as if it was the only element predicated, as the element that accepts within its own structure of meaning the meaning of the noun, altering it to mean what the adjective does, as the potential dimension where any possible parameter of meaning can be integrated as part 
of that dimension of meaning. This fact is extremely illustrative in Spanish in the case of the so called adjetivo epiteto,

\section{la blanca nieve.}

The potential capability of the adjective is the element that puts together, alters and integrates the other element of meaning into its own structure of meaning. 'Nieve', in the example, is a mere specification and a restriction of the adjective 'blanca'. Even the determiner in the combination appears as a parameter of meaning in the structure of meaning of the adjective, as the element which extends the meaning of the adjective, giving it an absolute value: «the whiteness of the snow, the absolute whiteness of the snow, so that the snow is an aspect of the absolute whiteness».

These different predicative implications of both syntactic functions can be seen in all kinds of adjectives. Adjectives can be classified in accordance with the degree of abstraction of the state of affairs they denote in the language. We can distinguish abstract and concrete adjectives; adjectives establishing an abstract predication, and adjectives establishing a concrete predication. 'Old' is a typical concrete adjective. The differences between both syntactic predicative functions can be seen in the abstract predication as well: in,

a comprehensive theory,

the thing primarily predicated is the character of inclusion of everything essential on the part of the theory, whereas in,

a theory which is comprehensive,

the condition of including everything essential is only a characterictic of the theory. Other examples,

a clear explanation as against the explanation appeared clear; cogent arguments as against his arguments were cogent and coercive.

This is perhaps the most direct consequence of the predication established by adjectives considered from the point of view of the semantic implications in the state of affairs in the combination, but the most important role of the predication established by adjectives is the effect they have on the nouns they are combined with. The meaning of the combination of adjective plus noun is made up of the different elements of meaning given by both components, but it is a new 
one and, in the great majority of cases, it is unique and exists only once. The predication consists in the relationships in meaning established in the combination, that is, it basically consists in the capability of the adjective to accept the components of meaning of the noun within its own structure of meaning, with the resulting alteration produced on the noun. The resulting meaning basically consists of the meaning of the adjective. The predicative force of the adjective consists in the capability of establishing relationships of signification between both components of the combination, and in the alteration of the meaning of the noun it produces. The meaning of the adjective is the guidelines according to which the meaning of the combination is to be interpreted. The meaning of the adjective, consisting especially of relationships of signification amongst the components that make up their structure of meaning, as against the meaning of the noun consisting of an element denoting a particular kind of object - hence the capability of designation in nouns-, takes up the content of the noun as one of the possible executions of the parameters of meaning in its own structure of meaning. In this respect we can distinguish two predicative functions performed by the adjective in the combination. The predicative function of definition of the noun, and the predicative function of application of its content on the content of the noun.

\subsection{The definition of the state of affairs in the noun}

The combination of the state of affairs conveyed by the adjective and the state of affairs conveyed by the noun has, as its most immediate result, the application of the content of the adjective on the content of the noun. The result is that the state of affairs of the noun is altered in such a way that the state of affairs of the noun denotes only one kind of the many possible kinds of semantic objects that can be denoted by it. The following examples illustrate this,

\footnotetext{
... a very good school; ...good agricultural land; she put her good shoes on; I get very good marks; she speaks good English; ...wandering through the West End in search of good theatre (examples from the Collins Cobuild English Language Dictionary).
}

It is clear, from the knowledge of things in the real world, from the general principles of knowledge, and from the context in these examples, that the communicative purpose in the examples is to remark that there are, respectively, good and bad schools, good and bad agricultural lands, that she has pairs of good and worn shoes, that there are good and bad marks at school, that the English spoken can be good and bad, and that there is good and bad theatre. In 
every case the question is to denote those objects, not others, in opposition to all the others. Basically there is not any description in the examples. The possible descriptive character that all these adjectives convey, even in these examples, is blurred because of the fundamental classifying function in them. In

\section{I get very good marks}

there is a descriptive character as well, but the communicative purpose of the expression is to separate and contrast those marks that are very good from those that are not so good. The fundamental predicative function of the adjective in these cases is to classify the kind of possible semantic objects denoted by the noun. The result is an alteration of the meaning conveyed by the noun, that allows us to speak of a classification of the possible objects denoted in it.

The definition of the state of affairs in the noun by the state of affairs in the adjective, something that has to do with the combination of both states of affairs, and can freely be used by speakers although it is in the language previously performed (the norm of the language, cf. Coseriu, 1982: 94-104) where the most typical examples are to be found, is something that belongs to the predicative nature of adjectives. The predicative function of adjectives is the element that lets create examples such as,

a criminal lawyer, an eager student, as against a hungry man (Bolinger, 1967: 20-21); economic problem, accidental death, short circuit, as oposed to, a truthful person (Warren, 1984b: 113-114).

The predicative function of adjectives can be executed at anytime in the linguistic act, and the interpretation of the combination is to be made in accordance with the knowledge of real things and with the background that affects the linguistic act (cf. Coseriu, 1992: 114-132).

\subsection{The application of the content of the adjective to the content of the noun}

The predication established by the adjective in the combination of adjective plus noun consists in the projection of the state of affairs of the adjective on the state of affairs of the noun. This projection sometimes has as its most immediate result the creation of a new meaning where the content of the adjective is present, that is, it is a description of a particular object or some determined 
particularized objects of the kind of objects denoted by the noun. In this case the emphasis and the result of the predication has to do with individuals, that is, with semantic objects already determined and particularized in one way or another so that a new semantic object, not a kind of semantic objects, is described. This predicative function, then, has a descriptive character on the semantic object denoted in the noun, and the noun appears as a state of affairs completely different from the kind of semantic objects denoted by the noun. The state of affairs denoted by the noun is restricted with the state of affairs denoted by the adjective. The adjective adds its content to the content of the noun, and both create a new state of affairs. As an illustration we can analyse the following examples:

he is reading a good book; ...good news; ... a good feeling; it is good that there are places like this; they were taught to share, and that can only be good; we were fighting for a good cause; its a good thing that I wasn't there (examples from the Collins Cobuild English Language Dictionary).

In these cases the purpose of the communicative act is not to establish and separate different kinds of semantic objects but to describe the kind of objects denoted, projecting the content of the adjective on the content of the noun, thus creating new and different semantic objects. These objects denote particular semantic objects with designation in the real world, that is, they are previously determined, and thus orientated to real things. The result is that the content of the noun is a new semantic object different from the semantic object denoted without the contribution of the adjective. In the first example, the state of affairs could have been

\section{he is reading a book,}

and the communicative purpose of the expression would have been achieved: $a$ book, and, a good book, appear as two different states of affairs belonging to the same type of semantic states of affairs. They both are determined and particularized with the same determiner, and they both have the same indefinite designation. The contribution of the adjective, by its mere participation, creates a new semantic object, projecting its content on the content of the noun.

But, as said earlier, these two predicative functions coexist in a combination. The adjective, at the same time as it describes, defines the state of affairs in the noun. 
These two predicative functions of definition and application, have been interpreted in a different way by Dwight Bolinger (Bolinger, 1967), J. Teyssier (Teyssier, 1968) and Beatrice Warren (Warren, 1984b). They all coincide as to the different classes of adjectives although they differ in the names. Teyssier and Warren distinguish three kinds of modifiers of nouns: descriptors, classifiers and identifiers, and Bolinger distinguishes between reference-modification and referent-modification. They justify their distinctions differently:

there must be a tacit agreement between speaker and audience that entities of the description in question do indeed form a subcategory or special kind (Warren, 1984b: 11);

and, these two functions depend on

the nature of nouns, which both name classes and designate individuals (Bolinger, 1967: 23).

I The yuestion is that adjectives perform these two predicative functions; that they are predicative elements which perform the function of predicating of something in two different ways; that these functions have to do with the combination of adjectives with nouns, that is, with the predication established by adjectives; that, as with the rest of linguistic expressions, the combination of adjective plus noun is influenced by and is to be interpreted in accordance with the knowledge of real things and the principles of general knowledge (Coseriu, 1992: 132-136); and that the combination is a instrument of communication used with the purpose of establishing a social relationship of communication between speaker and listener (Dik, 1981: 1). The adjective projects its content on the content of the noun and makes up different relationships of predication, accepting within their own structure of predication the relationships of signification given by the noun, as the execution of one or some of their own parameters of meaning. The result is that the adjective defines the content of the noun, on the one hand, thus making up a classification of the possible kinds of semantic objects denoted by it, and alters the state of affairs predicated by the noun, thus creating a new semantic object, which, as it is usually determined by the instruments of determination, proper of the noun, designate particular semantic objects with existence in the real world.

\section{CONCLUding REMARKS}

Adjectives are elements of meaning constituting a structure of meaning made up of different relationships of signification amongst the parameters that 
define it. They exist and have been created with the exclusive purpose of functioning in the language: they extend their own parameters of meaning in the combination where they appear, create relationships of signification beyond their own structure of meaning and on the base of their own structure of meaning, and classify the kinds of semantic objects in the noun and project their meaning on the noun, thus contributing to the purpose of communication in a system of communication. Due to their character and to their function we can separate the aspects of meaning and function in them, distinguishing a structure of meaning, which is the expression of an open dimension of meaning not defined or specified in itself but with possibilities of definition and specification at any of its points, and a structure of predication, which acts and functions on the noun in two aspects, with the function of definition of the noun and with the function of application. In both cases it is the adjective that projects on the noun, the adjective that expands its structure of meaning in accordance with the parameters of meaning it is made up of.

\section{REFERENCES}

AARTS, J. M. G. \& J. P. CALBERT (1979): Metaphor and Non-Metaphor: the Semantics of Adjective-Noun Combinations, Tubingen, Max Niemeyer Verlag.

BOLINGER, Dwight (1967): «Adjectives in English: Attribution and Predication», Lingua 18, pages 1-34.

COSERIU, Eugenio (1981): Principios de semántica estructural, 2nd edition, Madrid, Gredos.

- (1982): Teoría del lenguaje y lingüistica general: cinco estudios, 3rd edition, Madrid, Gredos.

- (1985): El hombre y su lenguaje: estudios de teorla y metodología lingülstica, First published in 1977, Madrid, Gredos.

- (1992): Competencia lingüistica: elementos de la teoría del hablar, Spanish translation, Madrid, Gredos.

Dik, S. C. (1981): Functional Grammar, First published 1978, Amsterdam, NorthHolland.

LuNG, Magnus (1970): English Denominal Adjectives, A Generative Study of the Semantics of a Group of High-Frequency Denominal Adjectives in English, Gothenburg Studies in English, 21, Goteborg, Acta Universitatis Gothenburgensis.

Martí Mingorance, Leocadio (1984): «Lexical Fields and Stepwise Lexical Decomposition in a Contrastive English-Spanish Verb Valency Dictionary", Lexeter '83 Proceedings: Papers from the International Conference on Lexicography at Exeter, 9-12 September 1983, Tübingen, Max Niemeyer, pages 226-236. 
- (1985): «La semántica sintagmática del adjetivo: parámetros para la organización de un lexicón inglés/español de valencias adjetivales», Actas del segundo Congreso Nacional de Lingüística Aplicada, Madrid, pages 329-340.

- (1990): «Functional Grammar and Lexematics in Lexicography», J. Tomaszczyk y B. Lewandowska-Tomaszczyk, eds, Meaning and Lexicography: Selected Papers from the International Conference on Theories of Meaning and Lexicography, Amsterdam, John Benjamins, pages 227-253.

MARTINEZ Del CASTILlo, Jesús Gerardo (1991a): «La gradabilidad del adjetivo», Atlantis XIII, no 1 y 2 noviembre, pages 21-35.

- (1991b): «La estructura de predicado de los adjetivos intensificativos», Revista Española de Lingütstica Aplicada 7, pages 23-33.

QUIRK, Randolph; SIDNEY GREENBAUM; Geoffrey Leech; \& Jan SVARTVIK (1985): $A$ Comprehensive Grammar of the English Language, London and New York, Longman.

WARREN, Beatrice (1984a): Classifying Adjectives, Goteborg, Gothenburgensis Studies in English 56.

- (1984b): «The function of modifiers of nouns», Quaderni di Semantica V, vol 1, Junio 1984, pages 111-123. 